\title{
Información exógena y su impacto sobre la evasión en Colombia $\left(2001\right.$ - 2009) ${ }^{1^{*}}$
}

\author{
Ruth Alejandra Patiño Jacinto \\ Orlando Darío Parra Jiménez ${ }^{* * *}$ \\ Fredy Yesid León Mesa ${ }^{* * * *}$
}

Patiño J., R. A., Parra J., O. D. y León M., F. Y. (2010). Información exógena y su
impacto sobre la evasión en Colombia (2001-2009). Revista Activos, 15, 75-99.

JEL: H26

Recibido: 11 de octubre de 2010 Aprobado: 15 de diciembre de 2010

\section{Resumen}

El presente trabajo constituye una aproximación al tema de información exógena; parte de la revisión de lo conceptual y de los cambios principales en esta para luego presentar una estimación de la incidencia que tuvo sobre la evasión de impuestos en Colombia desde el 2005 hasta la fecha, utilizando un comparativo de la evasión en años anteriores (2001-

1 Artículo de reflexión derivado de la investigación denominada "El impacto del requerimiento de la información exógena en la evasión de impuestos nacionales en Colombia”, financiado por la Unidad de Investigación y Posgrados de la Universidad Santo Tomás y realizado en los años 2009 y 2010.

* Artículo producto de proyectos de investigación.

** Contadora Pública, profesora de tiempo completo de la Facultad de Contaduría Pública de la Universidad Santo Tomás, Bogotá.

*** Economista, profesor de tiempo completo de la Facultad de Negocios Internacionales de la Universidad Santo Tomás, Bogotá.

**** Contador Público, profesor de tiempo completo de la Facultad de Contaduría Pública de la Universidad Santo Tomás, Bogotá. 
2004) y el periodo en el cual ya se encuentra en vigencia la información exógena. Dicha estimación se realiza por medio de un modelo econométrico. La metodología utilizada consiste en el análisis de cointegración y el uso de vectores con mecanismos de corrección de error. La modelación concluyó que la información exógena incide en la reducción de la evasión de manera importante desde su aplicación en el año 2005.

\title{
Palabras clave
}

Información exógena, evasión, impuestos, administración tributaria

\author{
Patiño J., R. A., Parra J., O. D. and León M., F. Y. (2010). Exogenous information \\ and its impact on evasion in Colombia (2001-2009). Activos Review, 15, 75-99.
}

\begin{abstract}
This work approaches the issue of exogenous information. It starts with the review of the conceptual and major changes in it, and then provides an estimate of the impact it had on tax evasion in Colombia since 2005 to date, using a comparison of tax evasion in previous years (2001-2004) and the period which is already in place exogenous information. This estimation is performed through an econometric model, the methodology is the analysis of co-integration and use of vectors with error correction mechanisms. The modeling concluded that the exogenous information affects the reduction of tax evasion significantly since its implementation in 2005.
\end{abstract}

\section{Keywords}

Exogenous information, evasion, tax, tax administration

Patiño J., R. A., Parra J., O. D. et León M., F. Y. (2010). Information exogène et impact sur l'évasion en Colombie (2001-2009). Revue Activos, 15, 75-99.

\section{Résumé}

Le présent travail constitue une approche du thème de l'information exogène, partie de la révision du conceptuel et des changements principaux dans celle-ci pour présenter ensuite une estimation de l'incidence qu'elle a eue sur l'évasion fiscale en Colombie, depuis 2005 jusqu'à nos jours, en se basant sur une comparaison entre l'évasion fiscale dans les années précédentes (2001-2004) et la période dans laquelle l'information exogène est déjà en vi- 
gueur. Cette estimation se réalise au moyen d'un modèle économétrique. La méthodologie utilisée consiste en l'analyse de cointégration et l'utilisation de vecteurs avec mécanismes de correction d'erreurs. La modélisation a conclu que l'information exogène met en évidence une importante réduction de l'évasion fiscale depuis son application en 2005.

\section{Mots-clé}

Information exogène, évasion fiscale, impôts, administration fiscale

\section{Introducción}

La política fiscal colombiana ha pasado por múltiples reformas tributarias, desarrolladas a partir del proceso de apertura económica que se dio en los años noventa. El objetivo de dichas reformas era obtener estabilidad fiscal, la que se deterioró por el aumento de la deuda pública y la disminución de recursos arancelarios que proporcionaba el modelo de economía cerrada, reformas que en su estructura no han sido determinantes en este proceso de cambio y que generaron una inestabilidad constante en la normatividad fiscal del país.

Muchas de las medidas adoptadas para aumentar el recaudo llevaron a que estas reformas tributarias tengan presente nuevos impuestos, pero la pregunta es: ¿sirven de algo las distintas reformas tributarias que se hacen para la reducción de la evasión? Esta incógnita deja al descubierto muchos problemas que el gobierno tiene con el recaudo de los impuestos, y que podrían causar un aumento de la evasión al crear un nuevo impuesto o incorporar una nueva tarifa para los ya existentes.

De acuerdo con Patiño y Parra (2009, p. 7):

El concepto de evasión más sencillo es el no cumplimiento de un hecho frente a una normatividad; desde el punto de vista económico y enmarcado en términos de política fiscal, se puede entender como el no pago de un tributo que se realiza de forma consciente y predeterminada.

Este es un fenómeno que afecta directamente el erario público y por esta razón es una preocupación generalizada por parte del Estado.

Con el fin de mejorar los mecanismos de recaudo y los indicadores de eficiencia frente a la disminución de la evasión, se han creado distintas estrategias, como el requerimiento 
de información exógena, el modelo único de ingresos, servicios y control automatizado (Muisca), entre otros.

La información exógena:

Es el conjunto de datos que las personas naturales y jurídicas deben presentar periódicamente a la DIAN, según resolución expedida por el Director General, sobre las operaciones con sus clientes o usuarios. Quien debe presentar dicha información es el representante legal de la empresa o su apoderado (DIAN, 2007).

Por otro lado, el sistema Muisca es el modelo de gestión de la DIAN, el cual tiene como propósito "propender por la apropiación de mejores prácticas en todos los niveles de la organización”.

En Colombia la información exógena ha dado indicios de convertirse en un mecanismo adecuado para disminuir la evasión, ya que las cifras de recaudo se incrementaron. Los datos presentados permiten a la administración tributaria hacer el cruce de la información de una manera efectiva y en el tiempo establecido por la normatividad, permitiendo a la misma identificar los posibles desvíos en los ingresos que corresponden a los contribuyentes. Es así como el presente artículo busca identificar la relación que ha tenido el requerimiento de la información exógena en la evasión de impuestos en Colombia, en el periodo comprendido entre los años 2001 y 2009.

\section{¿Qué es información exógena?}

La administración de los impuestos y las aduanas recauda bastantes recursos para el país, por lo cual la gestión es tema fundamental del Estado, pues mediante esta se pretende que el área fiscal de la nación sea productiva y logre altos índices de rentabilidad mediante un gran sistema o modelo de gestión y administración.

La información exógena en Colombia nace de la implementación del sistema Muisca (modelo único de ingresos, servicios y control automatizado), el cual modernizó toda la gestión tributaria del país optimizando procesos que llevaron a la reducción de la evasión, desde su implementación en el 2005. 
De acuerdo con el plegable emitido por la DIAN para la presentación de información exógena año gravable 2008, esta "es el conjunto de datos que las personas naturales y jurídicas deben presentar periódicamente a la DIAN (Dirección de Impuestos y Aduanas Nacionales) sobre las operaciones con sus clientes y usuarios" (DIAN, 2008).

La DIAN denomina a estas personas naturales y jurídicas como los sujetos pasivos, que deben transmitir la información en formatos de datos de archivos $\mathrm{XML}^{2}$ que puedan viajar por internet, cumpliendo con las especificaciones técnicas reglamentadas en los esquemas $\mathrm{XSD}^{3}$ propuestos, utilizando un mecanismo de firma digital.

Un archivo XML es un conjunto de registros magnéticos en un estándar específico; se basa en documentos de texto plano en los que se utilizan etiquetas para delimitar los elementos de un documento. "Un esquema XSD es la descripción de la estructura de la información contenida en un archivo XML y de sus reglas, por ejemplo, la longitud y el tipo del campo, y la obligación de sus datos" (Hernández, 2006). De acuerdo con Li, Kang y Zhu (2009), con los archivos XML, los datos pueden intercambiarse entre sistemas incompatibles. Los sistemas informáticos y las bases de datos contienen datos que generalmente están en formatos incompatibles; convertir los datos a XML es de gran ayuda para reducir esta complejidad y crear datos que pueden leerse a través de diferentes tipos de aplicaciones.

La firma digital, mecanismo utilizado por la DIAN, certifica la presentación electrónica de las declaraciones o información exógena, sustituyendo la firma autógrafa de la persona natural, que actúa a nombre propio o como representante legal en documentos informáticos que se presentan. De acuerdo con DIAN (s.f.):

Se entiende como un valor numérico que se adhiere a un documento electrónico y que, utilizando un procedimiento matemático conocido, vinculado a la clave del suscriptor y al contenido del documento, permite determinar que este valor se ha obtenido exclusivamente con la clave del suscriptor y que el documento inicial no ha sido modificado después de efectuada la transformación, lo que permite garantizar la identidad del firmante y la integridad del texto o mensaje enviado.

2 Extensible Markup Language (lenguaje de marcas extensible).

3 Es un lenguaje de esquema utilizado para describir la estructura y las restricciones de los contenidos de los documentos XML. 


\section{Cambios representativos en la información exógena}

La Dirección de Impuestos y Aduanas Nacionales (DIAN), como ente recaudador, exige de forma obligatoria la presentación de información exógena. Como entidad del Estado, esta se convierte en uno de los mayores entes de gestión del país, debido al volumen de información que se maneja y procesa, para identificar los declarantes y omisos ante el fisco.

La obligación de presentar información exógena para las entidades públicas y privadas comenzó a regir desde el año gravable 2005, pero desde 1989 algunas entidades debían presentar información en medios magnéticos al ente recaudador, en ese entonces, la Dirección de Impuestos Nacionales (DIN), hoy DIAN. En el año gravable 2006 se logró avanzar en una reforma estructural del sistema tributario, definiéndose las personas, entidades y contribuyentes obligados a informar por el periodo gravable 2006.

Para el año gravable 2007 no se presentaron cambios en la presentación de información exógena tributaria que se reportó a la DIAN. Los contribuyentes obligados a suministrar información fueron los mismos, el tipo de datos mostrados o los medios por los cuales se entregó la información no cambió, ni siquiera cambió la estructura de los formatos.

La información exógena tributaria reportada por el periodo gravable 2008 presentó cambios importantes, tanto en calidad como en volumen de información entregada, y un aumento de los reportantes de la misma, con lo cual se confirma el interés de la DIAN en la información suministrada por los contribuyentes.

Por último, para el año gravable 2009, en las resoluciones emitidas el 28 de julio del mismo no se ven grandes cambios, ya que los topes mínimos para presentar reportes, o los terceros por incluir dentro de los mismos y los formatos de presentación de información, son iguales al año gravable 2008. Sin embargo, se evidencian cambios en las fechas de reporte, ya que ahora coinciden con la presentación de la declaración del impuesto sobre renta.

En la siguiente tabla se resume gran parte de los cambios de las resoluciones existentes, desde que se estableció la presentación de información exógena: 
Tabla 1. Resoluciones y sus principales cambios

\begin{tabular}{|c|c|}
\hline AÑO & Cambios representativos de la información por presentar \\
\hline 2005 & Comenzó a exigirse la información exógena a entidades públicas y privadas. \\
\hline 2006 & $\begin{array}{l}\text { Se definieron las personas, entidades y contribuyentes obligados a informar, } \\
\text { como entidades del sector financiero, cámaras de comercio, Bolsa de Valores } \\
\text { y comisionistas de bolsa, Registraduría Nacional del Estado Civil, notarios, } \\
\text { tipógrafos y litógrafos, grupos económicos y/o empresariales, entidades que } \\
\text { celebren convenios de cooperación, personas naturales y jurídicas, y demás } \\
\text { entidades. Toda esta información está contenida en formatos específicos de } \\
\text { acuerdo con el tipo de transacciones que reporte el ente (anexo 1). }\end{array}$ \\
\hline 2007 & $\begin{array}{l}\text { No se presentaron cambios circunstanciales en cuanto a las personas que } \\
\text { estuvieran obligadas a suministrar información, ni tampoco por el tipo } \\
\text { de datos presentados o los medios por los cuales se presentó la misma, ni } \\
\text { siquiera cambió la estructura de los formatos de presentación que se dio en } \\
\text { las resoluciones emitidas en el año } 2006 \text {. }\end{array}$ \\
\hline 2008 & $\begin{array}{l}\text { Se incorporó más información de la presentada en el año gravable } 2007 \text { para } \\
\text { todas las entidades vigiladas por la Superfinanciera, como lo son fondos de } \\
\text { empleados que realicen actividades financieras y cooperativas de ahorro y } \\
\text { crédito. Entre los cambios más representativos, se emitió información de } \\
\text { todas las cuentas bancarias con consignaciones superiores a } \$ 25.000 .000 \\
\text { en año, incluidos préstamos otorgados y saldos superiores a } \$ 5.000 .000 \text { en } \\
\text { cuentas corrientes y de ahorros a } 31 \text { de diciembre de } 2008 \text {. Dentro de estos } \\
\text { cambios se encuentran los de los CDT y otros títulos valores, para lo cual la } \\
\text { DIAN bajó los topes de reportes de información de } \$ 25.000 .000 \text { a } \$ 5.000 .000 \text {; } \\
\text { pero los ahorros voluntarios no se quedaron por fuera, los que se encuen- } \\
\text { tran en fondos mutuos de inversión y similares reportaron a personas con } \\
\text { saldos ahorrados superiores a } \$ 5.000 .000 \text {, y los fondos de pensiones fueron } \\
\text { reportados sin importar el monto; para los usuarios de tarjetas de crédito } \\
\text { se redujeron los topes. }\end{array}$ \\
\hline
\end{tabular}




\begin{tabular}{|c|c|}
\hline & $\begin{array}{l}\text { Para notarios, tipógrafos, bolsas y comisionistas de bolsa, en el año gravable } \\
2008 \text { cambió el tipo de información exógena por presentar; por ejemplo, los } \\
\text { notarios informaron la totalidad de las operaciones de compra y venta de } \\
\text { bienes y derechos que se efectuaron en sus notarías, pero con la novedad para } \\
\text { ese año de incluir el número de la notaría, código de municipio y de depar- } \\
\text { tamento; los comisionistas de bolsa reportaron a las personas o entidades a } \\
\text { cuyo nombre efectuaron durante el } 2008 \text { operaciones de compra o venta de } \\
\text { acciones y demás papeles transados en bolsa. Las bolsas, a su vez, reportaron } \\
\text { igualmente, y como lo han venido haciendo, la totalidad de las operaciones } \\
\text { hechas por cada comisionista. }\end{array}$ \\
\hline 2008 & $\begin{array}{l}\text { Para reportes de socios, costos y gastos e ingresos, las modificaciones fue- } \\
\text { ron en: asociados a cooperativas, los cuales se reportaron con participación } \\
\text { mayor a } \$ 5.000 .000 \text {, estas también deben reportar en el reglón de utilidades } \\
\text { y dividendos el valor del fondo de protección de aportes, y se reportaron de } \\
\text { igual forma todos los socios extranjeros de empresas. En cuanto a los costos } \\
\text { y gastos, se redujeron los topes para el reporte de pago a terceros, pasando } \\
\text { de } \$ 1.000 .000 \text { a } \$ 100.000 \text {, y los pagos por salarios y demás rentas de forma } \\
\text { individual pagada al tercero pasaron de } \$ 20.000 .000 \text { a } \$ 10.000 .000 \text {. Por la } \\
\text { parte de los ingresos, se crea un nuevo concepto, "ingresos obtenidos por } \\
\text { intereses sobre créditos hipotecarios", y el tope por ingresos obtenidos con } \\
\text { un tercero, reportado en forma individualizada, se reduce de } \$ 5.000 .000 \text { a } \\
\$ 1.000 .000 \text {. En cuanto a los reportes de pasivos y cuentas por cobrar, no se } \\
\text { encontraron grandes cambios. }\end{array}$ \\
\hline 2009 & $\begin{array}{l}\text { No se ven grandes cambios, ya que los topes mínimos para presentar repor- } \\
\text { tes, o los terceros por incluir dentro de los mismos y hasta los formatos de } \\
\text { presentación de información, son iguales al año gravable 2008. En donde se } \\
\text { evidencian cambios es en las fechas de presentación, ya que son las mismas } \\
\text { en las que se presenta el impuesto de renta. }\end{array}$ \\
\hline
\end{tabular}

Fuente: Elaboración propia a partir de la información de la DIAN

\section{¿Hacia dónde va la información exógena?}

En Colombia, la información exógena se ha convertido en un mecanismo adecuado para el control fiscal de los contribuyentes; es así como datos presentados desde la información 
contable permiten a la administración tributaria hacer el cruce de información de una manera efectiva y en el tiempo establecido por la normatividad, permitiendo a la misma identificar los posibles desvíos en los ingresos que corresponden a los contribuyentes. Sería posible en este caso pensar que a partir de la información que estos presenten se estaría creando un mecanismo de control fiscal, apoyado en ellos mismos.

Con la implementación del sistema Muisca, año a año la remisión de información exógena experimenta cambios técnicos, que van desde la manera de entregar la información, el tipo de formato que debe entregarse o enviarse, hasta el tamaño de cada una de las casillas que contienen la información, entre otros. El Muisca, alimentado con la información exógena que presentan las personas naturales y jurídicas, ha hecho parte fundamental de la fiscalización y liquidación de la DIAN, ya que con los cruces de información se puede establecer:

1. Omisos declarantes (obligados que no declaran).

2. Inexactos (obligados que declaran, pero no lo hacen de acuerdo con la ley tributaria).

3. Declaración sombra ${ }^{4}$, que se obtiene del cruce de información de terceros (información exógena).

Dentro de la información propia que la DIAN posee, se encuentra el registro único tributario de las declaraciones presentadas y las autorizaciones de facturación, siendo estas para la DIAN información endógena, la cual cruza contra el extracto fiscal, que es el detalle de todas las transacciones económicas hechas por el contribuyente e informadas por terceros, durante un determinado periodo gravable, lo que representa para la DIAN información exógena.

El artículo publicado en el portal Actualicese.com (2007), titulado "Se repite la historia: esta vez son 350.000 las personas naturales omisas por no declarar renta 2006”, confirma que la información exógena ha contribuido en los últimos años a reducir la evasión. Es el caso de la información exógena reportada en el año gravable 2006, donde la DIAN encontró que 350.000 personas naturales no cumplieron con la obligación de presentar renta, por lo cual pasaron a formar parte del universo de los omisos. Pero no solamente con la presentación del impuesto de renta por parte de los omisos se ha podido demostrar la reducción de la evasión, sino porque en los últimos años la participación fiscal en el porcentaje del PIB ha venido en aumento con respecto a los años anteriores a la implementación de la información exógena. 
Otra evidencia de reducción en la evasión es el aumento del recaudo de los impuestos, al ser el IVA y la Renta los dos más representativos del país y los cuales, sumados, incorporan el 85\% del recaudo de los impuestos nacionales, principal fuente del presupuesto nacional, con índices de evasión en el año 2002 del 40\% en la Renta y 26\% en IVA; para el año 2006 los porcentajes pasaron al $31 \%$ y $21 \%$, respectivamente.

Reyes-Moncada (2007) señala en entrevista a Óscar Franco Charry (ex Director de Impuestos y Aduanas Nacionales), "en el año 2002, el recaudo de impuestos a cargo de la DIAN fue de 27,5 billones de pesos; en el 2006 ascendió a 52,7 billones de pesos”. Para el año 2007 el recaudo fue de 60,3 billones de pesos, lo cual representó un 14,0\% del PIB. Según informe de gestión presentado por la DIAN, en el año 2008 se recaudaron 67 billones de pesos, lo cual significó un 14,2\% del PIB. Este incremento en el recaudo es bastante notorio, como lo muestra la figura 1, pero un aspecto para tener en cuenta es que el incremento se dio en varios sentidos, especificados en las reformas tributarias realizadas, entre los cuales se encuentra el control de la información, el incremento en las tarifas y en las bases gravables, y la creación de nuevos impuestos como en el caso del GMF (gravamen a los movimientos financieros), el cual inicialmente era temporal.

Figura 1

Recaudo bruto de la DIAN como proporción del PIB

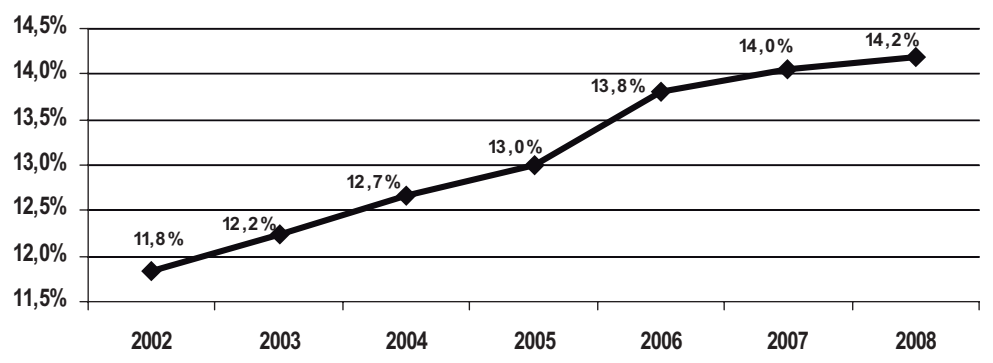

Fuente: Proyección de ingresos. Oficina de Estudios Económicos. DIAN. Ingresos tributarios administrados por la DIAN 1970 - 2007. En: www.dian.gov.co.

Desde la implementación del sistema Muisca, para la alimentación del mismo con la información exógena, se evidencia una disminución gradual de la evasión, con un aumento significativo en el recaudo y un crecimiento en el pago de impuestos por parte del contribuyente. 
Para el año 2009 se espera lograr un recaudo de impuestos por parte de la DIAN por 73,1 billones de pesos, 6 billones más que lo recaudado en el 2008, con lo cual se contribuirá a cubrir el gasto del presupuesto nacional.

Figura 2. Recaudo bruto DIAN 2008 - 2009

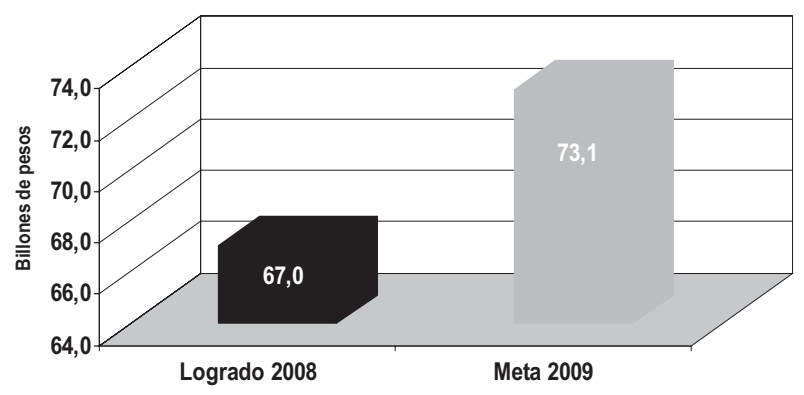

Fuente: Coordinación de Estudios Económicos - Subdirección de Gestión de Análisis Operacional - DIAN.

\section{Modelo de medición de incidencia de la información exógena en la evasión}

El objetivo de este apartado es evaluar la incidencia que ha tenido la información exógena sobre tres variables señaladas: tasa impositiva, base imponible y evasión.

De acuerdo con Patiño y Parra (2010), la metodología usada en el modelo consiste en el análisis de cointegración y la posterior modelación a través de un vector con mecanismos de corrección de error, complementado por un análisis de filtro Holdrick Prescot, el cual permite suavizar la serie de evasión frente a los cambios de la Renta y el IVA. Esto hace posible analizar el impacto de la evasión en la economía, ya que tales modelos permiten determinar la relación de largo plazo de la variable dependiente (evasión) y establecer la influencia de la dinámica de las variables independientes en el corto plazo.

La cointegración por medio de VEC permite realizar un análisis dinámico de corto plazo, mientras que no es posible para el largo plazo por la naturaleza misma de la metodología. El análisis de cointegración es esencial cuando se tiene una combinación de variables que presenten una similitud en el orden de integración. Intuitivamente, el hecho de que el error sea estacionario indica que las series presentan una tendencia en común. Si estas cointegran la regresión entre las dos variables, es significativa y no se pierde información 
valiosa de largo plazo, lo cual sucedería si se estima la regresión en primeras diferencias. Las ventajas de este modelo es que considera un conjunto de variables relevantes para el modelo, estima la ecuación incluyendo un determinado número de rezagos para cada variable y realiza un proceso de reducción eliminando los que no son estadísticamente significativos.

En primera instancia, con el ánimo de conocer la forma en que cada una de las variables señaladas incide sobre el recaudo del impuesto $i$, debe estimarse la siguiente relación:

$R_{i}=\alpha+\beta * t_{i}+\gamma * B_{i}-\delta * e_{i}+d+e_{i} * d$

Donde $\alpha, \beta, \gamma$ y $\delta$ son los parámetros por estimar para el impuesto $i$. Esta estimación debería proporcionar información sobre cómo cada una de aquellas variables afectan el recaudo. Sin embargo, debido a la falta de información sobre algunas de ellas de manera precisa y los requerimientos de información de alta frecuencia y periodos prolongados, se hace necesaria la utilización de un modelo reducido que permita una estimación más robusta.

De la ecuación (1) es posible incluir al PIB como proxy para capturar el efecto de la evasión sobre el recaudo y, de manera indirecta, si la información exógena ha tenido resultados positivos desde su implementación. La inclusión de esta variable se justifica porque existe una fuerte asociación entre ella con los principales impuestos, a pesar de que no puede captar las modificaciones sobre la base. Otro motivo se basa en el interés que genera el efecto ciclo económico sobre el recaudo. Entre los efectos más importantes se encuentra la presión fiscal ${ }^{5}$; es posible que un aumento positivo en el PIB genere una menor presión fiscal y de esta manera se produzca un mayor recaudo.

De este modo, se puede establecer una ecuación que defina la evasión teniendo en cuenta sus principales determinantes:

$e_{i}=\rho+\varepsilon * P I B+\varphi * t_{i}+\omega * G A P+d$

donde GAP es el gasto de la administración pública, $d$ es una variable dummy que trata de capturar el efecto de la información exógena sobre el recaudo y, en particular, si esta tiene alguna incidencia sobre la evasión. país. 


\section{Resultados}

De acuerdo con las variables estudiadas: recaudo, evasión con respecto a los impuestos de Renta e IVA, la información exógena contribuye a la disminución de la evasión en materia de recaudo de impuestos. Tomando como base el modelo trabajado en "Evasión de impuestos nacionales en Colombia: años 2001 - 2009” y añadiendo la información exógena como una variable de influencia sobre el recaudo de impuestos, el modelo muestra:

Tabla 2. Información estadística del modelo de información exógena

\begin{tabular}{|l|c|c|}
\hline \multicolumn{1}{|c|}{ Estadístico } & Sin información exógena & Con información exógena \\
\hline R-Squared & 0,026297 & 0,4637 \\
\hline Durbin Watson & 1,8798 & 1,998 \\
\hline Akaike & 2,81 & 2,84 \\
\hline
\end{tabular}

Fuente: Estimaciones propias

La información exógena afecta de manera directa el recaudo en casi dos puntos porcentuales, mejorando su comportamiento (reducción en la evasión de los impuestos alrededor de cuatro puntos porcentuales) y contribuyendo en la participación del PIB (14\%).

La autocorrelación del modelo permite establecer el impacto de la variable independiente (información exógena) con respecto a la dependiente (recaudo). De acuerdo con el anexo 3, Autocorrelación de la información exógena, el impacto es significativo.

Tabla 3. Variación de la evasión con respecto a la I.E. 2001 - 2009 (cifras en millones de pesos)

\begin{tabular}{|c|c|c|c|c|}
\hline & Evasión & $\begin{array}{c}\text { Información } \\
\text { exógena }\end{array}$ & $\begin{array}{c}\text { Evasión con } \\
\text { información exógena }\end{array}$ & Impacto \\
\hline 2001 & 6.163 & 1.622 & 4.541 & $26,3^{10 \tilde{U}}$ \\
\hline 2002 & 10.545 & 4.811 & 5.734 & $45,6^{2 \dot{U}}$ \\
\hline 2003 & 12.546 & 6.909 & 5.637 & $55,1^{3 \mathrm{U}}$ \\
\hline 2004 & 14.037 & 9.822 & 4.215 & 70,0 \\
\hline 2005 & 14.388 & 1.101 & 13.287 & 7,7 \\
\hline 2006 & 17.166 & 1.244 & 15.922 & 7,2 \\
\hline 2007 & 16.420 & 1.313 & 15.107 & 8,0 \\
\hline 2008 & 14.097 & 1.195 & 12.902 & 8,5 \\
\hline 2009 & 12.616 & 1.424 & 11.192 & 11,3 \\
\hline
\end{tabular}

Fuente: Estimaciones propias 
En general, la tabla 3 muestra que a partir del 2005, cuando se implantan los reportes de la declaración (información exógena) para entidades públicas y privadas y la implementación del sistema Muisca, la evasión de los impuestos con este medio disminuye el 7,7\% en el año 2005, aunque se ha incrementado a partir de dicho periodo hasta llegar a un estimado del 11,3\% en el 2009.

Antes del año 2005 si bien existían reportes exógenos, la información no es lo suficientemente completa y consolidada; de allí que la variación no sea confiable, por lo tanto no es relevante su análisis.

\section{Conclusiones}

Al conocer las cifras del recaudo de los impuestos a partir del año 2005, se encontró que la evasión, por lo menos en impuestos nacionales, disminuye de manera significativa, aproximadamente 4\%, con la implementación del sistema Muisca, el cual se alimenta con la información exógena proporcionada por los contribuyentes, lo que muestra la eficiencia del modelo, dada adicionalmente por la revisión constante de la normatividad aplicable.

La necesidad de ejercer control y adecuada administración tributaria es constante, y no se puede perder de vista que las estrategias utilizadas deben estar acordes con la actualidad, en donde la tecnología es una herramienta fundamental en muchos ámbitos, lo que contribuye al mejoramiento de las políticas públicas en materia de tributación. Para esto la DIAN desarrolló un medio de alimentación de datos y cruce de información de los contribuyentes, lo que le permite a esta una adecuada verificación en los tiempos estipulados por la normativa colombiana e identificando los posibles focos de evasión que se presentan en Colombia, con el fin de disminuirlos.

Una herramienta como la información exógena, la cual se compone por muchos datos apoyados es un sistema de control frente a la evasión, es acorde con las necesidades del entorno actual en el que es apremiante optimizar el recaudo de impuestos. 


\section{Referencias}

Actualicese.com (2005). Las estadísticas de Aranguren. Recuperado el 6 de julio de 2009, de http://www.actualicese.com/actualidad/2005/03/20/las-estadisticas-de-aranguren/

Actualicese.com (2006). Aviso de prensa para los usuarios obligados a utilizar los servicios informáticos electrónicos de la DIAN. Recuperado el 6 de julio de 2009, de http://www.actualicese.com/actualidad/2006/01/23/aviso-de-prensa-para-losusuarios-obligados-a-utilizar-los-servicios-informaticos-electronicos-de-la-dian/

Actualicese.com (2006). Cuestionario verificación reporte de medios magnéticos 2005 en el formato 1002. Recuperado el 6 de julio de 2009, de http://www.actualicese.com/ actualidad/2006/06/12/cuestionario-verificacion-reporte-de-medios-magnticos-2005en-el-formato-1002/

Actualicese.com (2006). Información exógena cambiaria - Se debe presentar virtual o presencialmente. Recuperado el 6 de julio de 2009, de http://www.actualicese.com/ actualidad/2006/10/30/informacion-exogena-cambiaria-se-debe-presentar-virtualo-presencialmente/

Actualicese.com (2006). ¿Qué pretende la DIAN al exigir el reporte de las retenciones asumidas durante el 2006? - Primera parte. Recuperado el 6 de julio de 2009, de http://www.actualicese.com/actualidad/2006/12/04/que-pretende-la-dian-al-exigirel-reporte-de-las-retenciones-asumidas-durante-el-2006-primera-parte/

Actualicese.com (2006).¿Qué pretende la DIAN al exigir el reporte de las retenciones asumidas durante el 2006? - Segunda parte. Recuperado el 6 de julio de 2009, de http://www.actualicese.com/actualidad/2006/12/04/que-pretende-la-dian-al-exigirel-reporte-de-las-retenciones-asumidas-durante-el-2006-segunda-parte/

Actualicese.com (2006). Tenga en cuenta los siguientes "tips" sobre la información a reportar en medios magnéticos 2005. Recuperado el 16 de junio de 2009, de http://www.actualicese.com/actualidad/2006/06/05/tenga-en-cuenta-los-siguientes$\%$ e2\%80\%9ctips\%e2\%80\%9d-sobre-la-informacion-a-reportar-en-medios-magneticos-2005/

Actualicese.com (2007). Especial: Información exógena tributaria a la DIAN por el año gravable 2007 - Primera parte. Recuperado el 6 de julio de 2009, de http://www. 
actualicese.com/actualidad/2007/11/02/especial-informacion-exogena-tributaria-ala-dian-por-el-ano-gravable-2007-primera-parte/

Actualicese.com (2007). Especial: Información exógena tributaria a la DIAN por el año gravable 2007 - Segunda parte. Recuperado el 6 de julio de 2009, de http://www. actualicese.com/actualidad/2007/11/02/especial-informacion-exogena-tributaria-ala-dian-por-el-ano-gravable-2007-segunda-parte/

Actualicese.com (2007). Especial: Información exógena tributaria a la DIAN por el año gravable 2007 - Tercera parte. Recuperado el 6 de julio de 2009, de http://www. actualicese.com/actualidad/2007/11/02/especial-informacion-exogena-tributaria-ala-dian-por-el-ano-gravable-2007-tercera-parte/

Actualicese.com (2007). Qué gana la DIAN al exigir la información exógena tributaria 2006 a partir de marzo 20 de 2007. Recuperado el 6 de julio de 2009, de http://www. actualicese.com/actualidad/2007/03/19/que-gana-la-dian-al-exigir-la-informacionexogena-tributaria-2006-a-partir-de-marzo-20-de-2007/

Actualicese.com (2007). Quiénes entregarán virtualmente el formato 1002 a la DIAN con las retenciones hechas durante el 2006. Recuperado el 6 de julio de 2009, de http://www.actualicese.com/actualidad/2007/06/03/quienes-entregaran-virtualmenteel-formato-1002-a-la-dian-con-las-retenciones-hechas-durante-el-2006/

Actualicese.com (2007). Se repite la historia: esta vez son 350.000 las personas naturales omisas por no declarar renta 2006. Recuperado el 6 de julio de 2009, de http://www. actualicese.com/actualidad/2007/10/15/se-repite-la-historia-esta-vez-son-350000-laspersonas-naturales-omisas-por-no-declarar-renta-2006/

Actualicese.com (2008). ¿Cómo se reportaría en información exógena el IVA descontable por compras de maquinarias industriales? Recuperado el 2 de julio de 2009, de http://www.actualicese.com/actualidad/2008/05/22/como-se-reportaria-eninformacion-exogena-el-iva-descontable-por-compras-de-maquinarias-industriales/

Actualicese.com (2008). ¿Cuánto tiempo tiene la DIAN para exigir una información exógena que no se le haya presentado? Recuperado el 2 de julio de 2009, de http:// www.actualicese.com/actualidad/2008/06/23/cuanto-tiempo-tiene-la-dian-paraexigir-una-informacion-exogena-que-no-se-le-haya-presentado/ 
Actualicese.com (2008). DIAN madrugó con las resoluciones sobre información exógena para 2009. Recuperado el 16 de junio de 2009, de http://www.actualicese.com/ actualidad/2008/05/13/mas-gente-debera-reportar-inf-exogena/

Actualicese.com (2008). DIAN modifica normatividad sobre información exógena de frigoríficos. Recuperado el 16 de junio de 2009, de http://www.actualicese.com/ actualidad/2008/04/25/dian-modifica-normatividad-sobre-reportes-de-informacionexogena-que-deberan-hacerle-a-los-frigorificos/

Actualicese.com (2008). Esto es lo que debe saber sobre información exógena tributaria a la DIAN por el año gravable 2007. Recuperado el 16 de junio de 2009, de http://www.actualicese.com/actualidad/2008/03/28/esto-es-lo-que-debe-saber-sobreinformacion-exogena-tributaria-a-la-dian-por-el-ano-gravable-2007/

Actualicese.com (2008). KPMG: Verificaciones para la información exógena nacional. Recuperado el 2 de julio de 2009, de http://www.actualicese.com/actualidad/2008/12/15/kpmg-verificaciones-para-la-informacion-exogena-nacional/

Actualicese.com (2008). La DIAN madrugó con las resoluciones de información exógena tributaria del año gravable 2008. Recuperado el 2 de julio de 2009, de http:// www.actualicese.com/actualidad/2008/11/27/la-dian-madrugo-con-resoluciones-deinformacion-exogena-tributaria-del-ano-gravable-2008/

Actualicese.com (2008). La evasión ganadera en la lupa de la DIAN. Recuperado el 16 de junio de 2009, de http://www.actualicese.com/actualidad/2008/02/01/evasionganadera-en-la-lupa-de-la-dian/

Actualicese.com (2008). Modificados reportes de socios, costos y gastos e ingresos del año - Cambios en información exógena - 4ta parte. Recuperado el 16 de junio de 2009, de http://www.actualicese.com/actualidad/2008/05/18/se-modifican-losreportes-de-socios-costos-y-gastos-e-ingresos-del-ano-iv-parte/

Actualicese.com (2008). Notarios, tipógrafos, bolsas y comisionistas deben hacer pequeños cambios en reportes para el 2008 - Cambios en información exógena - 2da parte. Recuperado el 16 de junio de 2009, de http://www.actualicese.com/ actualidad/2008/05/18/a-notarios-y-tipografos-les-hicieron-pequenos-cambios-ensus-reportes-para-el-2008-ii-parte/ 
ACTIVOS | Ruth Alejandra Patiño Jacinto, Orlando Darío Parra Jiménez y Fredy Yesid León Mesa

Actualicese.com (2008). Reglamentan reporte de información exógena de quienes ejecuten convenios de cooperación internacional. Recuperado el 16 de junio de 2009, de http://www.actualicese.com/actualidad/2008/01/20/reglamentan-reporte-deinformacion-exogena-de-quienes-ejecuten-convenios-de-cooperacion-internacional/

Actualicese.com (2008). Respuestas de la DIAN a interrogantes de los contadores públicos. Recuperado el 2 de julio de 2009, de http://www.actualicese.com/actualidad/2008/08/12/respuestas-de-la-dian-a-cuestionamientos-de-los-contadores-publicos/

Actualicese.com (2008). Sector financiero reporta más datos en el 2008 - Cambios en información exógena. Recuperado el 16 de junio de 2009, de http://www.actualicese. com/actualidad/2008/05/18/las-entidades-del-sector-financiero-reportaran-masdatos-que-los-reportados-por-el-ano-2007-i-parte/

Actualicese.com (2008). Serán muchos más los obligados a reportar información del art. 631 - Cambios en información exógena - 3ra parte. Recuperado el 16 de junio de 2009, de http://www.actualicese.com/actualidad/2008/05/18/por-el-2008-seranmuchos-mas-los-obligados-a-entregar-la-informacion-del-art631-iii-parte/

Actualicese.com (2008). 13 recomendaciones para la preparación de información exógena tributaria a la DIAN año gravable 2007. Recuperado el 16 de junio de 2009, de http://www.actualicese.com/actualidad/2008/01/25/recomendaciones-parala-preparacion-de-informacion-exogena-tributaria-a-la-dian-ano-gravable-2007/

Actualicese.com (2009).¿Cuánto tiempo tiene la DIAN para detectar errores de fondo a los reportes de información exógena tributaria? Recuperado el 6 de julio de 2009, de http://www.actualicese.com/actualidad/2009/06/08/cuanto-tiempo-tiene-la-dianpara-detectar-errores-de-fondo-a-los-reportes-de-informacion-exogena-tributaria/

Actualicese.com (2009). Especial: Información exógena tributaria a la DIAN por el año gravable 2009 - En los reportes del artículo 631 se hicieron algunos cambios importantes. Recuperado el 6 de julio de 2009, de http://www.actualicese.com/ actualidad/2009/08/03/especial-informacion-exogena-tributaria-a-la-dian-por-elano-gravable-2009-en-los-reportes-del-articulo-631-se-hicieron-algunos-cambiosimportantes/ 
Actualicese.com (2009). Especial: Información exógena tributaria a la DIAN por el año gravable 2009 - Introducción. Recuperado el 6 de julio de 2009, de http://www. actualicese.com/actualidad/2009/08/03/especial-informacion-exogena-tributaria-ala-dian-por-el-ano-gravable-2009-introduccion/

Actualicese.com (2009). Especial: Información exógena tributaria a la DIAN por el año gravable 2009 - Sector financiero, notarios, tipógrafos, bolsas de valores y comisionistas reportarán con los mismos topes del 2008. Recuperado el 6 de julio de 2009, de http://www.actualicese.com/actualidad/2009/08/03/especial-informacion-exogenatributaria-a-la-dian-por-el-ano-gravable-2009-sector-financiero-notarios-tipografosbolsas-de-valores-y-comisionistas-reportaran-con-los-mismos-topes-del-2008/

Actualicese.com (2009). Hasta los reportantes de exógena de los años 2006 y 2007 quedaron ahora obligados a declarar virtualmente. Recuperado el 6 de julio de 2009, de http://www.actualicese.com/actualidad/2009/02/02/hasta-los-reportantes-de-exogena-de-los-anos-2006-y-2007-quedaron-ahora-obligados-a-declarar-virtualmente/

Actualicese.com (2009). KPMG: Declaraciones virtuales y firmas digitales. Recuperado el 6 de julio de 2009, de http://www.actualicese.com/actualidad/2009/02/23/kpmgdeclaraciones-virtuales-y-firmas-digitales/

Actualicese.com (2009). Las correcciones a los reportes de exógena exigen un cuidado especial con el nombre de los archivos. Recuperado el 6 de julio de 2009, de http:// www.actualicese.com/actualidad/2009/05/18/las-correcciones-a-los-reportes-deexogena-exigen-un-cuidado-especial-con-el-nombre-de-los-archivos/

Actualicese.com (2009). ¿Quiénes son los nuevos obligados a declarar virtualmente desde octubre de 2009? Recuperado el 6 de julio de 2009, de http://www.actualicese. com/actualidad/2009/08/05/quienes-son-los-nuevos-obligados-a-declarar-virtualmente-desde-octubre-de-2009/

Actualicese.com (2009). Recomendaciones importantes para quienes presentan información exógena a la DIAN. Recuperado el 6 de julio de 2009, de http://www.actualicese.com/actualidad/2009/04/06/recomendaciones-importantes-para-reportantesde-informacion-exogena/

Actualicese.com (2009). Sociedades que se liquiden después de julio 28 de 2009 también tienen que entregar información exógena a la DIAN. Recuperado el 6 de julio de 
2009, de http://www.actualicese.com/actualidad/2009/08/10/sociedades-que-seliquiden-despues-de-julio-28-de-2009-tambien-tienen-que-entregar-informacionexogena-a-la-dian/

DIAN. Dirección de Impuestos y Aduanas Nacionales. (2004). Modelo único de ingresos, servicio y control automatizado. Unidad administrativa especial.

DIAN. (2007).Presentación de información exógena presencial. [En línea].http://www. dian.gov.co/descargas/plegables/plegableExogena_2007.pdf

DIAN. (2008). Informe de gestión. Unidad administrativa.

DIAN. (2008). Presentación de información exógena presencial año gravable 2008 a presentarse en el 2009. Plegable 3.

DIAN. (s.f.). Mecanismo digital. Recuperado el 24 de noviembre de 2010, de http://www. dian.gov.co/_05256ed00058986a.nsf/0/0a85816f18cff2b2052570f90003ba03?Ope nDocument

García-Molina, M. (2005). ¿Han aumentado el recaudo las reformas tributarias en Colombia? En Revista de económica institucional, No. 12, pp. 43-61. ALyC.

Hernández, J.A. (2006). Información tributaria exógena para la DIAN. En Revista de Orientación Tributaria Impuestos, No.138, pp. 27-29. Legis.

Li, Y., Kang, F. \& Zhu, M. (2009, octubre). An XML-based Data Interchange Protocol and Supporting Systems for Online Customs Declaration. Proceedings of the 2009 IEEE International Conference on Systems, Man, and Cybernetics. San Antonio, TX, USA. Recuperado el 26 de noviembre de 2010, de http://www.bases.unal.edu. co:2365/stamp/stamp.jsp?tp=\&arnumber $=5346663$

Patiño, R. \& Parra, O. (2009). Evasión de impuestos nacionales en Colombia: años 2001 - 2009 (artículo de reflexión en proceso de evaluación). Bogotá: Universidad Santo Tomás.

Ramírez, M.C. (2007). Servicios informáticos electrónicos de la DIAN: administración moderna y práctica. En Revista de Orientación Tributaria Impuestos, No. 142, pp. 2-6. Legis. 
Reyes-Moncada, E. (2007). El Muisca disminuye cada vez más la evasión y los delitos fiscales. En Revista de Orientación Tributaria Impuestos, No. 142, pp. 7-10. Legis.

Rojas, J.N. (2006). ¿Llegó la hora de una reforma tributaria estructural? En Revista de Orientación Tributaria Impuestos, No. 133, pp. 4-16. Legis.

\section{Anexos}

Anexo 1. Formatos de presentación de información exógena

$\left.\begin{array}{|l|l|c|}\hline \text { Formato } & \multicolumn{1}{|c|}{\text { Concepto }} & \begin{array}{c}\text { Orden } \\ \text { del anexo }\end{array} \\ \hline 1010 & \text { Información de socios y accionistas } & 1 \\ \hline 1001 & \text { Pagos o abonos en cuenta } & 2 \\ \hline 1002 & \text { Retenciones en la fuente practicadas } & 3 \\ \hline 1003 & \text { Retenciones en la fuente que le practicaron } & 4 \\ \hline 1004 & \text { Descuentos tributarios } & 5 \\ \hline 1005 & \text { Ingresos recibidos } & 6 \\ \hline 1006 & \text { Impuesto a las ventas por pagar (descontable) } & 7 \\ \hline 1007 & \text { Impuesto a las ventas por pagar (generado) } & 10 \\ \hline 1009 & \text { Saldo de las cuentas por pagar a 31 de diciembre } & 11 \\ \hline 1008 & \text { Saldo de las cuentas por cobrar a 31 de diciembre } & 12 \\ \hline 1011 & \text { Información de las declaraciones tributarias } & 13 \\ \hline 1012 & \begin{array}{l}\text { Información de las declaraciones tributarias, acciones } \\ \text { y aportes e inversiones en bonos, certificados, títulos y } \\ \text { demás inversiones tributarias }\end{array} & \begin{array}{l}\text { Información de pagos o abonos en cuenta a través de } \\ \text { consorcios y uniones temporales }\end{array} \\ \hline 1043 & \begin{array}{l}\text { Información de retenciones en la fuente practicadas a } \\ \text { través de consorcios y uniones temporales }\end{array} \\ \hline 1046 & \begin{array}{l}\text { Información de ingresos recibidos por consorcios y } \\ \text { uniones temporales }\end{array} & 16 \\ \hline \text { Información de pagos o abonos en cuenta de los contratos } \\ \hline 1045\end{array}\right)$




\begin{tabular}{|c|c|c|}
\hline 1047 & $\begin{array}{l}\text { Información de retenciones en la fuente practicadas a } \\
\text { través de los contratos de asociación para la exploración } \\
\text { y explotación minera }\end{array}$ & 17 \\
\hline 1048 & $\begin{array}{l}\text { Información de ingresos recibidos de los contratos de } \\
\text { asociación para la exploración y explotación minera }\end{array}$ & 18 \\
\hline 1049 & $\begin{array}{l}\text { Impuesto sobre las ventas por pagar (descontable) en } \\
\text { contratos de asociación para la exploración y explotación } \\
\text { minera }\end{array}$ & 19 \\
\hline 1050 & $\begin{array}{l}\text { Impuesto a las ventas por pagar (generado) en contratos } \\
\text { de asociación para la exploración y explotación minera }\end{array}$ & 20 \\
\hline 1051 & $\begin{array}{l}\text { Saldo en cuentas por cobrar a } 31 \text { de diciembre en contra- } \\
\text { tos de asociación para la exploración y explotación minera }\end{array}$ & 21 \\
\hline 1052 & $\begin{array}{l}\text { Saldo en cuentas por pagar a } 31 \text { de diciembre en contratos } \\
\text { de asociación para la exploración y explotación minera }\end{array}$ & 22 \\
\hline 1016 & $\begin{array}{l}\text { Pagos o abonos en cuenta efectuados en contratos de } \\
\text { mandato o administración delegada }\end{array}$ & 23 \\
\hline 1053 & $\begin{array}{l}\text { Información en retención en la fuente practicada a través } \\
\text { de contratos de mandato o de administración delegada }\end{array}$ & 24 \\
\hline 1017 & $\begin{array}{l}\text { Ingresos recibidos por contratos de mandato o adminis- } \\
\text { tración delegada }\end{array}$ & 25 \\
\hline 1054 & $\begin{array}{l}\text { Impuesto a las ventas por pagar (descontable) en contratos } \\
\text { de mandato o de administración delegada }\end{array}$ & 26 \\
\hline 1055 & $\begin{array}{l}\text { Impuesto a las ventas por pagar (generado) en contratos } \\
\text { de mandato o de administración delegada }\end{array}$ & 27 \\
\hline 1027 & $\begin{array}{l}\text { Información de saldos de cuentas por pagar a } 31 \text { de } \\
\text { diciembre en contratos de mandato o administración } \\
\text { delegada }\end{array}$ & 28 \\
\hline 1018 & $\begin{array}{l}\text { Información de saldos de cuentas por cobrar a } 31 \text { de } \\
\text { diciembre en contratos de mandato o administración } \\
\text { delegada }\end{array}$ & 29 \\
\hline 1013 & Información de fideicomisos que administran & 30 \\
\hline 1014 & $\begin{array}{l}\text { Pagos o abonos en cuenta realizados con recursos del } \\
\text { fideicomiso }\end{array}$ & 31 \\
\hline 1015 & Retenciones en la fuente practicadas a través de fiducias & 32 \\
\hline
\end{tabular}




\begin{tabular}{|c|c|c|}
\hline 1056 & $\begin{array}{l}\text { Pagos o abonos en cuenta por secretarios generales que } \\
\text { administran recursos del tesoro }\end{array}$ & 33 \\
\hline 1057 & $\begin{array}{l}\text { Información de retenciones en la fuente practicadas por } \\
\text { secretarios generales que administran recursos del tesoro }\end{array}$ & 34 \\
\hline 1019 & Movimiento en cuentas corrientes y/o ahorro & 35 \\
\hline 1020 & Información de inversiones en CDT & 36 \\
\hline 1021 & $\begin{array}{l}\text { Inversión en fondos de valores, fondos de inversión, fon- } \\
\text { dos mutuos de inversión }\end{array}$ & 37 \\
\hline 1022 & Ahorro voluntario en fondos de pensiones & 38 \\
\hline 1023 & Consumos con tarjetas de crédito & 39 \\
\hline 1024 & Ventas con tarjetas de crédito & 40 \\
\hline 1026 & Préstamos bancarios otorgados & 41 \\
\hline 1025 & Diferencias contables y fiscales & 42 \\
\hline 1038 & Información de las sociedades cerradas & 43 \\
\hline 1039 & Sociedades liquidadas & 44 \\
\hline 1041 & Información de bolsa de valores & 45 \\
\hline 1042 & Información de comisionistas de bolsa & 46 \\
\hline 1034 & $\begin{array}{l}\text { Información de estados financieros consolidados - grupos } \\
\text { económicos }\end{array}$ & 47 \\
\hline 1035 & Subordinadas nacionales & 48 \\
\hline 1036 & Subordinadas del exterior & 49 \\
\hline 1037 & Elaboración de facturación por litógrafos y tipógrafos & 50 \\
\hline 1032 & $\begin{array}{l}\text { Información de enajenaciones de bienes y derechos a } \\
\text { través de notarías }\end{array}$ & 51 \\
\hline 1028 & Personas fallecidas & 52 \\
\hline 1059 & Identificación de convenios & 53 \\
\hline
\end{tabular}

Fuente: Elaboración propia con base en resoluciones de información exógena 2006, emitidas por la DIAN 
Anexo 2. Análisis estadístico de la información exógena

\begin{tabular}{|c|c|c|}
\hline Alternativa según & \multicolumn{2}{|c|}{ Alternativas según Oficio Circular 485} \\
\hline \multirow{3}{*}{$\begin{array}{l}\text { Presentación nor- } \\
\text { ma, full IFRS }\end{array}$} & Trimestrales & Anuales \\
\hline & $\begin{array}{l}\text { Opción “a” (original): "full” IFRS } \\
\text { (cifras } 2009 \text { comparativas con } \\
\text { 2008, ambas bajo IFRS) }{ }^{*}\end{array}$ & $\begin{array}{l}\text { "Full" IFRS: cifras } 2009 \text { com- } \\
\text { parativas con 2008, ambas } \\
\text { bajo IFRS* }\end{array}$ \\
\hline & $\begin{array}{l}\text { Opción "b": Sólo GAAP chileno } \\
\text { actual (cifras } 2009 \text { comparativas } \\
\text { con } 2008 \text {, ambas bajo GAAP) }\end{array}$ & \\
\hline \multirow[t]{2}{*}{$\begin{array}{l}\text { Alternativa punto } 2 \text {, } \\
\text { inc. "d": GAAP chi- } \\
\text { leno comparativo } \\
\text { e IFRS de una sola } \\
\text { columna en carác- } \\
\text { ter de proforma }\end{array}$} & $\begin{array}{l}\text { Opción "c" (original): GAAP chi- } \\
\text { leno (cifras } 2009 \text { comparativas } \\
\text { con 2008, ambas bajo GAAP) } \\
\text { más IFRS proforma de una sola } \\
\text { columna }(2009)^{\star \star}\end{array}$ & $\begin{array}{l}\text { GAAP chileno (cifras } 2009 \\
\text { comparativas con 2008, am- } \\
\text { bas bajo GAAP) más IFRS } \\
\text { proforma de una sola colum- } \\
\text { na }(2009)^{* *}\end{array}$ \\
\hline & $\begin{array}{l}\text { Opción "d”: Sólo GAAP Chileno } \\
\text { actual (cigras } 2009 \text { comparativas } \\
\text { con 2008, ambas bajo GAAP) }\end{array}$ & \\
\hline
\end{tabular}

Fuente: Informe especial preparado por Economía y Negocios on line de El Mercurio y Pricewatherhouse Coopers

* Se dispone de un plazo adicional de 30 días para su presentación.

** Se dispone de un plazo adicional de 30 días sólo para información IFRS. 
Anexo 3. Autocorrelación de la información exógena

Resumen columna "A partir de" y "Modalidad"

\begin{tabular}{|l|c|c|}
\hline \multicolumn{1}{|c|}{ A partir de } & Modalidad & No. Entidades \\
\hline & Full & 12 \\
\hline 31-12-2009 & Proforma & 99 \\
\hline 31-03-2009 & Full & 80 \\
\hline & Proforma & 2 \\
\hline 30-06-2009 & Full & 2 \\
\hline Total sociedades & Proforma & 3 \\
\hline
\end{tabular}

Fuente: S.V.S. 